\title{
Conditioning with a passive person reinforcer and extinction in Shetland sheep dog puppies'
}

\author{
Walter C. Stanley, NATIONAL INSTITUTE OF MENTAL HEALTH \\ Dale D. Morris, ARGONNE NATIONAL LABORATORY \\ Alice Trattmer, UNIVERSITY OF CALFORNIA, DAVS
}

\begin{abstract}
Abstraet
The Ss progressively increased their speed of running to a goal area containing a passive person and progressively decreased their speed when the person was absent. The passive person appears to be a positive (stimuluspresentation) rather than a negative (stimulus-termination) reinforcer in puppies.

\section{Problem}

If early social behavior is maintained by reinforcers inherent in social interactions, such reinforcers should be identifiable and subject to parametric study. Previous research on puppies has shown that contact with a passive person fulfills two criteria for defining a reinforcing event. These are: (a) greater improvement in, and maintenance of, behavior when the behavior leads to the event than when it does not (Stanley \& Elliot, 1962); and (b) differential level of performance dependent on the immediate prior history of deprivation of the event (Bacon \& Stanley, 1963). In the present experiment, evidence was sought on whether the passive person fulfilled the extinction criterion for defining a reinforcer. According to this criterion, presence of the person should produce progressive increments in performance while omission of the person should produce progressive decrements.

\section{Method}

The Ss were 18 purebred Shetland sheep dogs from four litters. They were weaned at $41 / 2 \mathrm{wk}$. and started in training at $6 \mathrm{wk}$. of age. The apparatus was a $3-\mathrm{ft}$ high white cloth enclosure $12 \times 111 / 2 \mathrm{ft}$, with a start box in one corner and a 3-x 3-ft goal square just under $10 \mathrm{ft}$ away. It differed from that of Stanley \& Elliot (1962) in having: the start box door of wood rather than hardware cloth; the start box at square 44 rather than 11; the goal square at 22 rather than 33; and a 4-ft wide screen between the goal square and the start box.

A P-NP-P group (3 males, 6 females) was run with a person present in Phase 1 , no person in Phase 2, and a person in Phase 3. An NP-P-NP group (3 males, 6 females) was run with no person in Phase 1, a person in Phase 2, and no person in Phase 3. Assignment' of Ss to groups was random except that litter and sex were equated insofar as possible. In the P-NP-P group $4 \mathrm{Ss}$ had a male and 5 a female goal person; in the NP-P-NP group 5 Ss had a male and 4 a female goal person.

There were 3 trials per day for 10 days per phase. The goal person put $S$ in the start box 15 sec. prior to $\mathrm{E}$ 's opening the start box door. A trial lasted $4 \mathrm{~min}$. or until $2 \mathrm{~min}$. after $\mathrm{S}$ reached the goal square, whichever was shorter. About $45 \mathrm{sec}$. intervened between trials within a daily session. The goal person was attired in

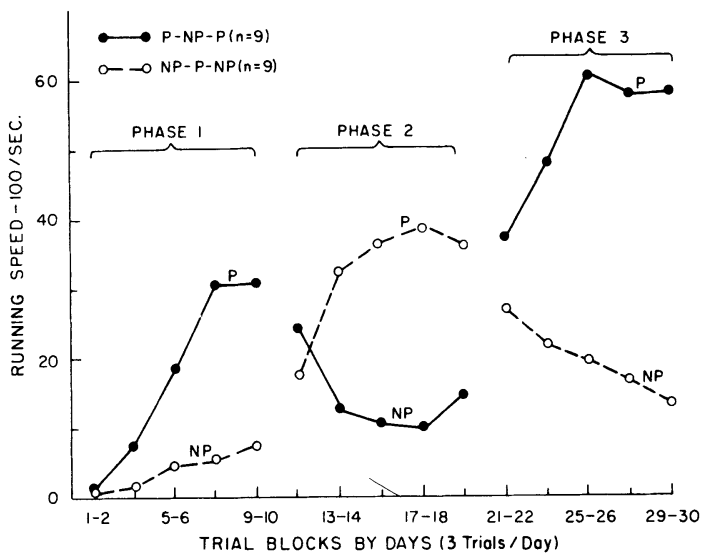

Fig. 1. Mean running speed plotted to show the source of the highest order signifricant interaction variance.

a white lab coat over regular clothing and sat passively in the goal square during $P$ phases.

Running time from S's leaving the start box to its crossing any line of the goal square was read from an electric timer to $0.1 \mathrm{sec}$. and transformed to a speed score, $100 / \mathrm{sec}$.

\section{Results}

In both groups performance progressively improved or declined depending on whether the person was, respectively, present or absent (Fig. 1). Analysis of variance with Groups, Phases, Trial blocks, and Trials within days as main factors showed that the highest order significant interaction was Group $\mathrm{X}$ Phases $\mathrm{X}$ Trial blocks, the interaction depicted in Fig. 1. The F was 11.6; conservative $\mathrm{df}, 1$ and 16 , and $\mathrm{p}<.01$. During Phase 1, running speed was greater under the $P$ than under the NP condition $(p<.01)$. During Phases 2 and 3 , the increase in running speed over blocks under the $\mathbf{P}$ conditions and the decrease in running speed over blocks under the NP conditions were reliable (ps< .05).

There was also a highly significant decrement in performance from one trial to the next within daily sessions. This decrement usually appeared after the first block in each phase in both groups (Fig. 2 and 3). The F for the Trial blocks $\mathrm{X}$ Trials within days interaction was $4.9(\mathrm{p}<.05)$ and that for Trials within days was 47.3 $(p<.01)$. The remaining significant sources of variance were: Phases $X$ Trials within days $(F=6.5 ; p<.05)$; Phases $X$ Groups $(\mathrm{F}=24.6 ; \mathrm{p}<.01)$; Trial Blocks $(F=13.8 ; p<.01)$; and Phases $(F=23.8 ; p<.01)$. All are based on a conservative 1 and $16 \mathrm{df}$. 


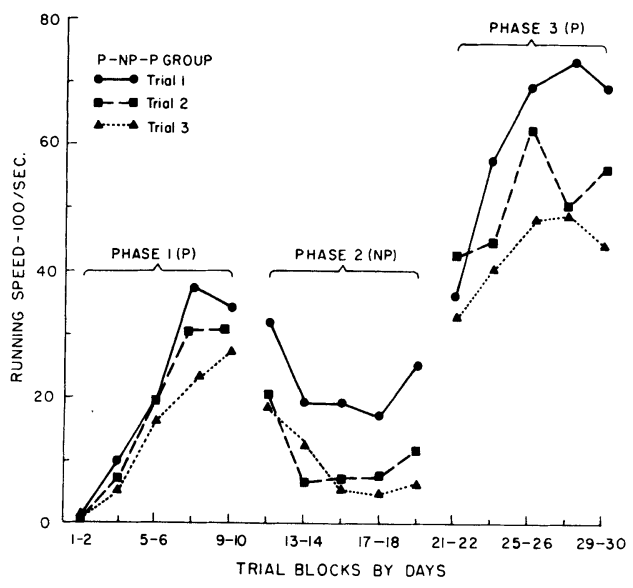

Fig. 2. Mean running speed of the P-NP-P Group, broken down according to trials within daily sessions.

\section{Diseussion}

The progressive increments and decrements in performance obtained show that conditioning occurred when the person was present and extinction when the person was omitted. Thus, in puppies, a passive person fulfills the extinction criterion for defining a reinforcer.

The temporary decrement in performance correlated with trials within daily sessions may represent, in part, a satiation effect (Stanley \& Elliot, 1962; Bacon \& Stanley, 1963). When the person was present, the satiation could have been related primarily to the person as a major source of reinforcement. When the person was absent, the satiation could have been related to.sources of reinforcement too weak to sustain performance at a high level; e. g., odors from the person or a previous $S$ having been in the goal square.

Can the nature of the passive person reinforcer be specified more exactly? Only tentatively, but Es' observations that Ss' playful and manipulatory behavior in response to the person seemed to increase with training trials and Bacon \& Stanley's (1963) finding that deprivation of the passive person reinforcer affects the asymptote of the curve of performance, together, suggest that the passive person reinforcer is a positive

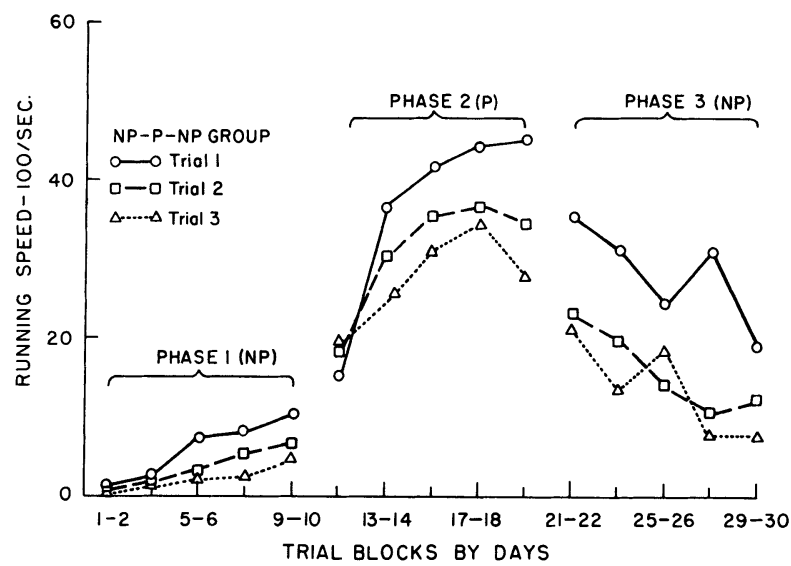

Fig. 3. Mean running speed of NP-P-NP Group, broken down according to trials within daily sessions.

(stimulus-presentation) rather than a negative (stimulus-termination) reinforcer. In line with this suggestion, it might prove fruitful to reassess experimentally and theoretically the possible role of positive reinforcers, as compared with emotional arousal (Scott, 1962) and anxiety (Moltz, 1960), in the emergence and maintenance of mammalian and avian social attachments.

\section{References}

BACON, W. E., \& STANLEY, W. C. Effect of deprivation level in puppies on performance maintained by a passive person reinforcer. J. comp. physiol. Psychol., 1963, 56, 783-785.

MOLTZ, H. Imprinting: empirical basis and theoretical significance. Psychol. Bull., 1960, 57, 291-314.

SCOTT, J. P. Critical periods in behavioral development. Science, $1962,138,949-958$.

STANLEY, W. C., \& ELLIOT, O. Differential human handling as reinforcing events and as treatments influencing later social behavior in basenji puppies. Psychol Rep., 1962, 10, 775-788.

Note

1. This research was carried out at the Jackson Laboratory and supported, in part, by PHS Grant M-4412 from the National Institute of Mental Health, Public Health Serivce. The authors express their gratitude to Thomas C. Snell, Anne Stebbins, Betsy A. Hamlin, and Geraldine Keene who aided in the collection or analysis of data. A preliminary report of this experiment was presented at the 1963 meeting of the American Psychological Ass. 